\title{
Identification of Novel Metabolites of Rosiglitazone in Freshly Isolated Human, Rat, and Monkey Hepatocytes by Liquid Chromatography/Tandem Mass Spectrometry
}

\author{
Minoru Uchiyama, ${ }^{1 *}$ Minoru Oguchi, ${ }^{2}$ Naotoshi Yamamura, ${ }^{1}$ Hiroko Koda, ${ }^{1}$ \\ Thomas Fischer, ${ }^{3}$ Juergen Mueller, ${ }^{3}$ Takashi Izumi, ${ }^{1}$ \\ and Haruo Iw ABUCHI ${ }^{1}$ \\ ${ }^{1}$ Drug Metabolism and Pharmacokinetics Research Laboratories, Daiichi Sankyo Co., Ltd., Shinagawa- \\ ku, TOKYO, JAPAN \\ ${ }^{2}$ Daiichi Sankyo RD Associe Co., Ltd., Shinagawa-ku, TOKYO, JAPAN \\ ${ }^{3}$ Drug Metabolism Department, Daiichi Sankyo Europe GmbH, München, GERMANY
}

\begin{abstract}
The in vitro metabolism of rosiglitazone (RGZ) was studied in freshly isolated human, rat, and monkey hepatocytes. The metabolites of $\left[{ }^{14} \mathrm{C}\right] \mathrm{RGZ}$ produced by incubation with hepatocytes were detected by radioactivity detection high-performance liquid chromatography. Seven metabolites (M1-M7) of RGZ were detected in human hepatocytes. The structures of the metabolites were elucidated by liquid chromatography/tandem mass spectrometry using electrospray ionization. The structural analysis demonstrated that M1, M2, and M4 were novel metabolites of RGZ. M1 was identified as a 2,4-thiazolidinedione (TZD) ring-opened $N$-glucuronide. M2 was identified as a TZD ring $N$-glucuronide. M4 was proposed to be a TZD ring-opened methylmercapto amide. Similarly, these metabolites were also detected in rat and monkey hepatocytes. To our knowledge, this is the first report on $\mathrm{N}$-glucuronidation of TZD rings. Based on the structures of the metabolites, we propose the following novel in vitro metabolic pathways for RGZ: 1) $N$-glucuronidation of the TZD ring of RGZ to form M2 followed by hydrolysis to the TZD ring-opened $N$-glucuronide M1; and 2) methylation of the mercapto group of the TZD ring-opened mercapto amide to form M4.
\end{abstract}

(Received October 2, 2009; Accepted November 2, 2009)

\section{Introduction}

The thiazolidinedione (TZD)-containing drug, rosiglitazone (RGZ, Fig. 1), is a potent antihyperglycemic agent ${ }^{1)}$ 2) that reduces insulin resistance in patients with type 2 diabetes mellitus. ${ }^{3)}$ RGZ is a member of the TZD class agents, a high-affinity ligand for peroxisome proliferator-activated receptor gamma (PPAR $\gamma$ ), a receptor subtype selectively expressed in adipocytes and shown to induce adipocyte differentiation. ${ }^{4)-8)}$

Several metabolites of RGZ in animals and humans have been reported. ${ }^{91-12)}$ The structures of most of the metabolites have been elucidated by liquid chromatography/tandem mass spectrometry (LC/MS/MS) using electrospray ionization (ESI). The major metabolites were oxidative products of the 2-methyl-2(pyridinylamino)ethyl moiety of RGZ and their sulfate and glucuronides.

Another TZD-containing drug, troglitazone (TGZ), was withdrawn from the market because of rare but serious cases of idiosyncratic hepatotoxicity. ${ }^{13), 14)}$ The generation of many reactive metabolites has been pro-

* Correspondence to: Minoru Uchiyama, Drug Metabolism and Pharmacokinetics Research Laboratories, Daiichi Sankyo Co., Ltd., 1-2-58 Hiromachi, Shinagawa-ku, Tokyo 1408710, JAPAN, e-mail: uchiyama.minoru.fe@daiichisankyo. co.jp posed in the in vitro metabolic experiments with TGZ. ${ }^{15)-21)}$ By LC/MS/MS analysis, Kassahun et al. ${ }^{15)}$ found that a sulfoxide, an $\alpha$-ketoisocyanate, and a sulfenic acid of TGZ were generated as reactive intermediates that easily react with glutathione in human liver microsomes or a human recombinant CYP3A4 system. Based on the discovery of the reactive metabolites and the presumed metabolic pathway, Kassahun et al. also reported the possible contribution of the reactive metabolites to the hepatotoxicity of TGZ. However, in contrast to TGZ, idiosyncratic hepatotoxicity has not been reported in the case of RGZ.

In this study, we performed a detailed search for the generated metabolites of RGZ in freshly isolated human, rat, and monkey hepatocytes by LC/MS/MS to clarify the metabolic pathways for RGZ.

\section{Experimental}

\subsection{Chemicals}

[TZD-5- $\left.{ }^{14} \mathrm{C}\right] \mathrm{RGZ}$ (specific radioactivity: $20 \mathrm{mCi} /$ mmol, radiochemical purity: >98\%) was synthesized by Blychem Ltd. (Billingham, UK). Collagenase $\mathrm{H}$ was purchased from Roche Diagnostics GmbH (Indianapolis, IN, USA). Hank's balanced salt solution (HBSS) was purchased from Mediatech, Inc. (Manassas, VA, USA). Ethyleneglycol-bis-aminoethylether- $N, N, N^{\prime}, N^{\prime}$ tetraacetic acid (EGTA), $S$-adenosyl-L-methionine (SAM), and acetobromo- $\alpha$-D-glucuronic acid methyl 


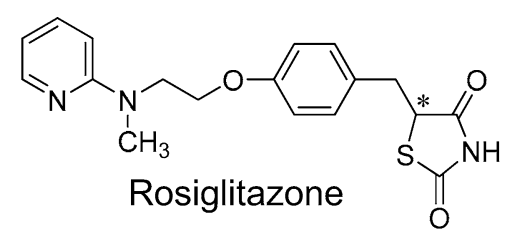

* indicates position of ${ }^{14} \mathrm{C}$ label<smiles>CN(CCOc1ccc(CC(SC(=O)NC2O[C@H](C(=O)O)[C@@H](O)[C@H](O)[C@H]2O)C(=O)O)cc1)c1ccccn1</smiles><smiles>CN(CCOc1ccc(CC2SC(=O)N([C@@H]3O[C@H](C(=O)O)[C@@H](O)[C@H](O)[C@H]3O)C2=O)cc1)c1ccccn1</smiles><smiles>CSC(Cc1ccc(OCCN(C)c2ccccn2)cc1)C(N)=O</smiles>

Fig. 1. Chemical structures of $\left[{ }^{14} \mathrm{C}\right] \mathrm{RGZ}$ and novel metabolites M1, M2, and M4.

ester were purchased from Sigma-Aldrich (St. Louis, MO, USA). $\quad N$-2-hydroxy ethylpiperadine- $N^{\prime}-2$ ethanosulfonic acid (HEPES) was purchased from Dojindo Laboratories (Kumamoto, Japan). Pooled human liver S9 from 15 donors was purchased from BD (Woburn, MA, USA). All other chemicals and solvents were of analytical or high-performance liquid chromatography (HPLC) grade.

\subsection{Animals}

A male Sprague-Dawley rat (Crl: CD, 7 weeks old) was purchased from Charles River Laboratories Japan Inc. (Kanagawa, Japan) and kept in a controlled animal area set at $23^{\circ} \mathrm{C}$ (within the limit of $20-26^{\circ} \mathrm{C}$ ) and $55 \%$ (within the limit of 30-70\%) relative humidity with a $12 \mathrm{~h}$ light-dark cycle of artificial lighting. The rat was given ad libitum access to food (FR-2; Funabashi Farm Co., Ltd., Chiba, Japan) and tap water, until the experiment for the preparation of the hepatocytes.

Two male cynomolgus monkeys (Macaca fasicularis, estimated age 5 years), obtained from Mitsubishi Chemical Safety Institute Ltd. (Ibaraki, Japan) or Hamri Co., Ltd. (Ibaraki, Japan), were kept in a controlled animal area set at $26^{\circ} \mathrm{C}$ (within the limit of $22-$ $28^{\circ} \mathrm{C}$ ) and $40 \%$ (within the limit of $30-70 \%$ ) relative humidity with a $12 \mathrm{~h}$ light-dark cycle of artificial lighting. Food (PS; Oriental Yeast Co., Ltd., Tokyo, Japan) was given once a day and ad libitum access to tap water was given to the monkeys, until the experiment for the collection of the liver.

2.3 Synthesis of TZD ring $N$-glucuronide (4) and TZD ring-opened $N$-glucuronide (5)

The TZD ring $N$-glucuronide and TZD ring-opened $N$-glucuronide were synthesized as outlined in Fig. 2, using the procedure described below.

Mass spectra were recorded using a JEOL JMS-700V, JEOL JMS-700QQ, or JEOL JMS-BU30 mass spectrometer (JEOL Ltd., Tokyo, Japan). Proton nuclear magnetic resonance $\left({ }^{1} \mathrm{H}\right.$ NMR) spectra were recorded using a JEOL JNM-AL400 (JEOL Ltd.), VARIAN Mercury 400, or VARIAN Mercury $400 \mathrm{Vx}$ spectrometer (Varian, Inc., Palo Alto, CA, USA) and were reported in parts per million $(\delta)$ downfield from the internal standard tetramethylsilane $\left(\mathrm{Me}_{4} \mathrm{Si}\right)$. All NMR spectra were consistent with the assigned structures. Column chromatography was performed on a Kishida reagent, silica gel SK-34, with a reported solvent. Thin-layer chromatography (TLC) analyses were performed on a Merck reagent, silica gel $60 \mathrm{~F}_{254}$ (0.25 mm thickness). Spots were visualized by either ultraviolet (UV) light or iodine.

$3-((2 R, 3 R, 4 S, 5 S, 6 S)-3,4,5$-Triacetoxy-6-methoxycarbonyl-tetrahydropyran- $2-y l)-5-\{4$-[2-(methyl- 2 -pyridinylamino)ethoxy]benzyl\}-thiazolidine-2,4-dione (2). $5.03 \mathrm{~g}$ (12.7 mmol) of acetobromo- $\alpha$-D-glucuronic acid methyl ester in $60 \mathrm{~mL}$ of acetonitrile was added to a solution of $3.00 \mathrm{~g}$ (6.34 mmol) of RGZ maleic acid salt (1) and 3.10 $\mathrm{g}(9.51 \mathrm{mmol})$ of cesium carbonate in $90 \mathrm{~mL}$ of acetonitrile, at $70^{\circ} \mathrm{C}$. The resulting mixture was stirred at $70^{\circ} \mathrm{C}$ for $3 \mathrm{~h}$. The reaction mixture was filtered with a silica gel short column (using a $1: 1$ by volume mixture of ethyl acetate and acetonitrile), and the filtrate was concentrated by evaporation under reduced pressure. The residue was purified by column chromatography with silica gel, using a gradient elution method with a mixture of hexane and ethyl acetate in ratios ranging from $1: 1$ to $1: 2$ by volume as the eluent, to give 4.00 g (5.94 mmol) of 2 : yield 94\%; mass spectrometry (MS) $m / z 674[\mathrm{M}+\mathrm{H}]^{+} ;{ }^{1} \mathrm{H}$ NMR $\left(\mathrm{CDCl}_{3}\right) \delta 1.9-2.1(9 \mathrm{H}, \mathrm{m}), 2.9$ $-3.0(1 \mathrm{H}, \mathrm{m}), 3.14(3 \mathrm{H}, \mathrm{d}, J=1.2 \mathrm{~Hz}), 3.4-3.6(1 \mathrm{H}, \mathrm{m}), 3.7-$ $3.8(3 \mathrm{H}, \mathrm{m}), 3.98(2 \mathrm{H}, \mathrm{dt}, J=2.8$ and $8.2 \mathrm{~Hz}), 4.1-4.2(1 \mathrm{H}$, $\mathrm{m}), 4.17(2 \mathrm{H}, \mathrm{dd}, J=5.6$ and $9.9 \mathrm{~Hz}), 4.36(1 \mathrm{H}, \mathrm{dt}, J=5.4$ and $15.5 \mathrm{~Hz}), 5.3-5.4(3 \mathrm{H}, \mathrm{m}), 5.94(1 \mathrm{H}, \mathrm{dt}, J=4.7$ and $13.1 \mathrm{~Hz}), 6.52(1 \mathrm{H}, \mathrm{d}, J=8.6 \mathrm{~Hz}), 6.56(1 \mathrm{H}, \mathrm{dd}, J=5.1$ and $7.0 \mathrm{~Hz}), 6.84(2 \mathrm{H}, \mathrm{dd}, J=5.5$ and $8.6 \mathrm{~Hz}), 7.10(2 \mathrm{H}, \mathrm{dd}, J=$ 

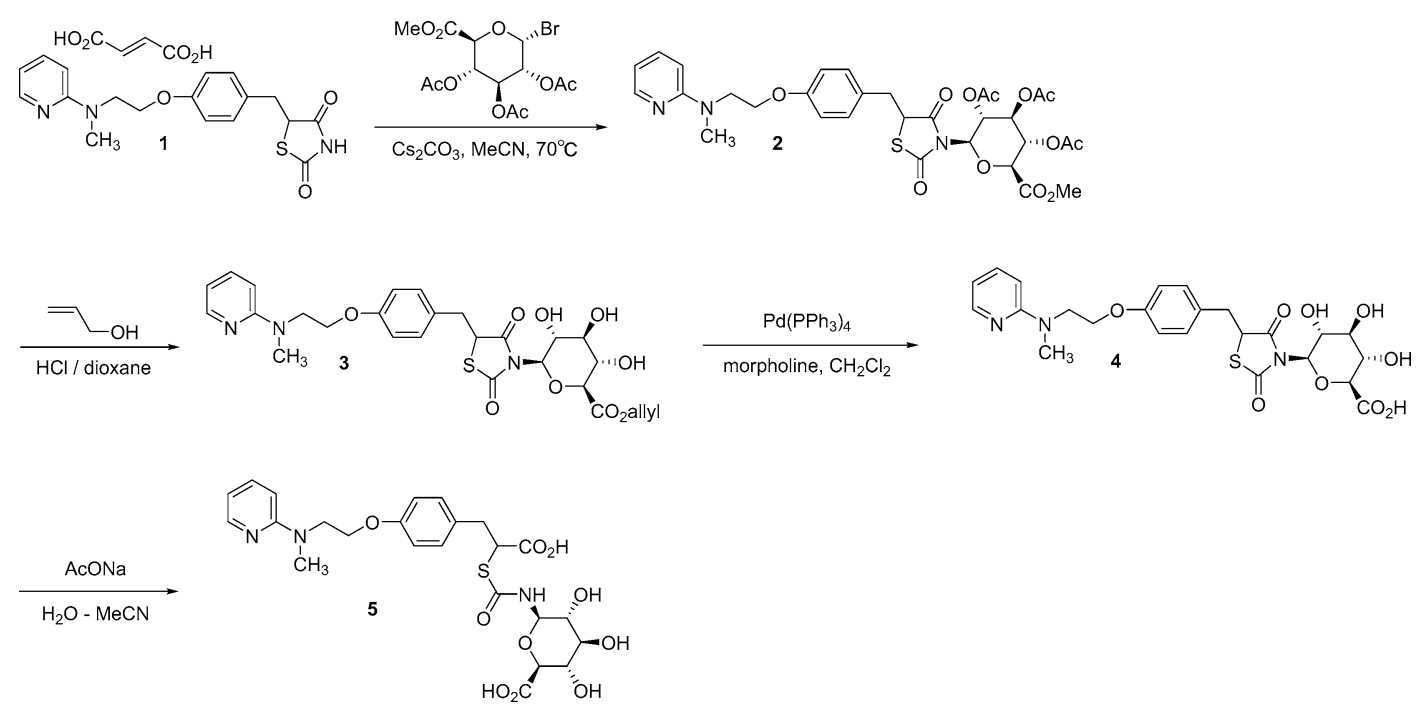

Fig. 2. Synthetic scheme of TZD ring $N$-glucuronide (4) and TZD ring-opened $N$-glucuronide (5).

1.6 and $8.6 \mathrm{~Hz}), 7.4-7.5(1 \mathrm{H}, \mathrm{m}), 8.15(1 \mathrm{H}, \mathrm{dd}, J=1.9$ and $5.1 \mathrm{~Hz})$.

$3-((2 R, 3 R, 4 S, 5 S, 6 S)-6$-Allyloxycarbonyl- $3,4,5$-trihydroxy-tetrahydropyran-2-yl)-5-\{4-[2-(methyl-2-pyridinylamino)ethoxy]benzyl -thiazolidine-2,4-dione (3). A solution of $4.00 \mathrm{~g}(5.94 \mathrm{mmol})$ of 2 and $80 \mathrm{~mL}$ of allyl alcohol in $80 \mathrm{~mL}$ of $4 \mathrm{~N}$ hydrogen chloride-dioxane was stirred at room temperature for $3 \mathrm{~h}$ and left standing at room temperature for 3 days. The reaction mixture was freed from the solvent by evaporation. The residue was diluted with a $5: 1$ by volume mixture of methylene chloride and 2-propanol, added to $150 \mathrm{~mL}$ of water, and treated with $1 \mathrm{~N} \mathrm{NaOH}$ solution, until the aqueous layer was acidified (until $\mathrm{pH} 4$ ). The organic layer was separated and the water layer was extracted with a $5: 1$ by volume mixture of methylene chloride and 2-propanol. The combined organic layers were washed with brine and dried over anhydrous sodium sulfate, after which the solvent was removed by evaporation under reduced pressure. The residue was purified by column chromatography with silica gel, using a gradient elution method with a mixture of methylene chloride and methanol in ratios ranging from $1: 0$ to $20: 1$ by volume as the eluent, to give $2.56 \mathrm{~g}(4.46$ mmol) of 3: yield $75 \%$; MS $m / z 574[\mathrm{M}+\mathrm{H}]^{+}$; ${ }^{1} \mathrm{H}$ NMR $\left(\mathrm{CDCl}_{3}\right) \delta 2.9-3.1(1 \mathrm{H}, \mathrm{m}), 3.12(3 \mathrm{H}, \mathrm{d}, J=2.0 \mathrm{~Hz}), 3.4-3.5(1$ $\mathrm{H}, \mathrm{m}), 3.5-3.7(1 \mathrm{H}, \mathrm{m}), 3.84(1 \mathrm{H}, \mathrm{t}, J=9.4 \mathrm{~Hz}), 3.9-4.0(3 \mathrm{H}$, $\mathrm{m}), 4.1-4.2(2 \mathrm{H}, \mathrm{m}), 4.43(1 \mathrm{H}, \mathrm{dd}, J=4.1$ and $9.2 \mathrm{~Hz}), 4.52$ (1 $\mathrm{H}, \mathrm{t}, J=9.2 \mathrm{~Hz}), 4.6-4.7(2 \mathrm{H}, \mathrm{m}), 5.13(1 \mathrm{H}, \mathrm{d}, J=9.4 \mathrm{~Hz})$, 5.2-5.3 (1H, m), 5.3-5.4 (1H, m), 5.8-6.0 (1H, m), 6.5-6.6 (2 $\mathrm{H}, \mathrm{m}), 6.81(2 \mathrm{H}, \mathrm{dd}, J=8.6$ and $9.6 \mathrm{~Hz}), 7.09(2 \mathrm{H}, \mathrm{dd}, J=8.6$ and $11.3 \mathrm{~Hz}), 7.4-7.5(1 \mathrm{H}, \mathrm{m}), 8.1-8.2(1 \mathrm{H}, \mathrm{m})$.

3 -((2R,3R,4S,5S,6S)-6-carboxy-3,4,5-trihydroxy-tetrahydropyran-2-yl)-5-\{4-[2-(methyl-2-pyridinylamino)ethoxy]benzyl\}-thiazolidine-2,4-dione (4). A mixture of $0.80 \mathrm{~g} \quad(1.39 \mathrm{mmol})$ of $3, \quad 0.16 \mathrm{~mL} \quad(1.83 \mathrm{mmol})$ of morpholine, and $0.32 \mathrm{~g}(0.28 \mathrm{mmol})$ of tetrakis(triphenylphosphine)palladium in $25 \mathrm{~mL}$ of methylene chloride was stirred at room temperature for $3 \mathrm{~h}$. The reaction mixture was freed from the solvent by evaporation. The residue was purified by column chromatography with silica gel, using a gradient elution method with a mixture of ethyl acetate, methanol, and water in ratios ranging from $30: 2: 1$ to $10: 2: 1$ by volume as the eluent, to give $0.54 \mathrm{~g}$ of pale yellow solid. This solid was purified using an SCL-10A HPLC system (Shimadzu Co., Kyoto, Japan). Separation was performed on an Inertosil ODS-3 column (50 mm $\times 500$ mm, $5 \mu \mathrm{m}$; GL Sciences, Inc., Tokyo, Japan) and UV detection was carried out at $254 \mathrm{~nm}$. The mobile phase, consisting of water containing $0.1 \%$ trifluoroacetic acid (TFA, solvent A) and acetonitrile (solvent B), was delivered at a flow rate of $50 \mathrm{~mL} / \mathrm{min}$. The gradient started at $10 \%$ solvent B and increased linearly to $35 \%$ solvent B for 60 min. The HPLC purification gave 0.45 $\mathrm{g}$ of TFA salt 4 : yield $59 \%$; MS $m / z 534[\mathrm{M}+\mathrm{H}]^{+} ;{ }^{1} \mathrm{H}$ NMR (DMSO-d 6 ) $\delta$ 2.9-3.2 (1H, m), $3.22(3 \mathrm{H}, \mathrm{s}), 3.2-3.5$ (3 $\mathrm{H}, \mathrm{m}), 3.71(1 \mathrm{H}$, dd, $J=9.6$ and $17.8 \mathrm{~Hz}), 4.0-4.3(5 \mathrm{H}, \mathrm{m})$, 4.7-5.1 (2H, m), 5.41 (3H, br s), 6.7-6.9 (3H, m), 7.1-7.2 (2 $\mathrm{H}, \mathrm{m}), 7.23(1 \mathrm{H}, \mathrm{d}, J=8.4 \mathrm{~Hz}), 7.91(1 \mathrm{H}, \mathrm{t}, J=7.5 \mathrm{~Hz}), 8.02$ $(1 \mathrm{H}, \mathrm{dd}, J=1.0$ and $6.1 \mathrm{~Hz}), 13.0(1 \mathrm{H}, \mathrm{br} \mathrm{s})$.

$(2 S, 3 S, 4 S, 5 R, 6 R)-6$-(1-Carboxy-2-\{4-[2-(methyl-2-py ridinylamino)ethoxy]phen yl\}-ethylsulfanylcarbonylamino)-3,4,5-trihydroxy-tetrahydropyran-2-carboxylic acid (5). A solution of $0.95 \mathrm{~g}(1.39 \mathrm{mmol})$ of 4 and $2.00 \mathrm{~g}(24.4 \mathrm{mmol})$ of sodium acetate in a $3: 1$ mixture of water and acetonitrile was stirred at room temperature for $5 \mathrm{~h}$. The reaction mixture was left standing at room temperature for 11 days. The reaction mixture was acidified with TFA (until pH 3). This mixture was purified using an SCL-10A HPLC system. Separation was performed on an Inertosil ODS-3 column (50 mm $\times 500 \mathrm{~mm}, 5 \mu \mathrm{m})$ and UV detection was carried out at $254 \mathrm{~nm}$. The mobile phase, consisting of water containing $0.1 \%$ TFA (solvent A) and acetonitrile (solvent $\mathrm{B}$ ), was delivered at a flow rate of 50 $\mathrm{mL} / \mathrm{min}$. The gradient started at $10 \%$ solvent $\mathrm{B}$ and increased linearly to $30 \%$ solvent B for $60 \mathrm{~min}$. HPLC purification gave $0.45 \mathrm{~g}$ of TFA salt 5 : yield $46 \%$; MS $m / z 552[\mathrm{M}+\mathrm{H}]^{+} ;{ }^{1} \mathrm{H}$ NMR $\left(\mathrm{DMSO}_{-} \mathrm{d}_{6}\right) \delta 2.89(1 \mathrm{H}, \mathrm{dd}, J=$ 6.3 and $13.8 \mathrm{~Hz}), 3.0-3.15(2 \mathrm{H}, \mathrm{m}), 3.22(3 \mathrm{H}, \mathrm{s}), 3.15-3.3$ $(2 \mathrm{H}, \mathrm{m}), 3.60(1 \mathrm{H}, \mathrm{dd}, J=1.6$ and $9.6 \mathrm{~Hz}), 4.00(2 \mathrm{H}, \mathrm{t}, J=$ $5.2 \mathrm{~Hz}), 4.09(1 \mathrm{H}, \mathrm{dd}, J=6.5$ and $8.7 \mathrm{~Hz}), 4.19(2 \mathrm{H}, \mathrm{t}, J=$ $5.2 \mathrm{~Hz}), 4.65-4.75(1 \mathrm{H}, \mathrm{m}), 5.20(3 \mathrm{H}, \mathrm{br} \mathrm{s}), 6.81(2 \mathrm{H}, \mathrm{d}, J=$ $8.6 \mathrm{~Hz}), 6.87(1 \mathrm{H}, \mathrm{t}, J=6.3 \mathrm{~Hz}), 7.11(2 \mathrm{H}, \mathrm{d}, J=8.6 \mathrm{~Hz})$, $7.22(1 \mathrm{H}, \mathrm{d}, J=7.4 \mathrm{~Hz}), 7.90(1 \mathrm{H}, \mathrm{t}, J=7.6 \mathrm{~Hz}), 8.01(1 \mathrm{H}$, 
dd, $J=0.9$ and $6.0 \mathrm{~Hz}), 9.00(1 \mathrm{H}, \mathrm{dd}, J=4.7$ and $8.6 \mathrm{~Hz})$, 12.7 (2H, br s).

\subsection{Preparation of freshly isolated human hepa-} tocytes

Human liver tissues from three donors were obtained from patients undergoing partial hepatectomy for metastatic liver tumors of colorectal cancer. Experimental procedures were performed according to the guidelines of the charitable state-controlled foundation, Human Tissue and Cell Research (HTCR, Regensburg, Germany), with informed patient's consent and approved by the local ethics committee of the University of Regensburg, Germany. The liver samples were made anonymous. The human hepatocytes used were isolated and provided by Hepacult GmbH (Regensburg, Germany), after being commissioned by HTCR and Daiichi Sankyo Europe $\mathrm{GmbH}$ (München, Germany). Cell isolation was performed using the modified two-step EGTAcollagenase perfusion procedure described by Weiss et $a l{ }^{22)}$ The hepatocytes were washed twice with HBSS and suspended in HBSS at the cell density of $2 \times 10^{6}$ cells $/ \mathrm{mL}$. As determined by the trypan blue dye exclusion method, the cellular viabilities of the hepatocytes were $81 \%, 73 \%$, and $66 \%$.

2.5 Preparation of freshly isolated rat and monkey hepatocytes

All experimental procedures were performed in accordance with the in-house guidance of the Institutional Animal Care and Use Committee of Daiichi Sankyo Co., Ltd.

Freshly isolated rat and monkey hepatocytes were obtained by the method described by Moldeus et al. ${ }^{23)}$ A male Sprague-Dawley rat (Crl: CD, 7 weeks old) was anesthetized by diethylether, and the abdomen was surgically opened to expose the portal vein. Sodium heparin solution was intravenously injected via the femoral vein. The rat liver was perfused with Hank'sHEPES buffer with 0.58 mM EGTA (Hank's-EGTA solution) for $3 \mathrm{~min}$ and then Hank's-HEPES buffer solution containing $5 \mathrm{mM} \mathrm{CaCl} 2$ and $1 \mathrm{mg} / \mathrm{mL}$ of collagenase (Hank's-collagenase solution) for $5 \mathrm{~min}$ at $37^{\circ} \mathrm{C}$. These media were gassed with $95 \% \mathrm{O}_{2}-5 \% \mathrm{CO}_{2}$ through perfusion. The Hank's-HEPES buffer solution contained the following: $135 \mathrm{mM} \mathrm{NaCl}, 5 \mathrm{mM} \mathrm{KCl}, 0.5$ $\mathrm{mM} \mathrm{MgSO}_{4}, 25 \mathrm{mM} \mathrm{NaHCO}_{3}, 0.34 \mathrm{mM} \mathrm{Na}_{2} \mathrm{HPO}_{4}, 0.44$ $\mathrm{mM} \mathrm{KH}_{2} \mathrm{PO}_{4}$, and $3 \mathrm{mg} / \mathrm{mL}$ HEPES. The rat hepatocytes were washed twice with HBSS and suspended in HBSS at the cell density of $2 \times 10^{6}$ cells/ $\mathrm{mL}$. The cellular viability of the rat hepatocytes was $93 \%$, as determined by the trypan blue dye exclusion method.

Two male cynomolgus monkeys (Macaca fasicularis, estimated age 5 years) were anesthetized with ketamine $(10 \mathrm{mg} / \mathrm{kg}$, intramuscular) and the abdomen was surgically opened to collect the liver. One lobe of the liver was cut off. A metal needle connected to a polyethylene tube was inserted into the portal vein. The monkey liver was perfused with Hank's-EGTA solution for 6 min and Hank's-collagenase solution for 10-11 min. The monkey hepatocytes were washed twice with HBSS and suspended in HBSS at the cell density of $2 \times 10^{6}$ cells $/ \mathrm{mL}$. As determined by the trypan blue dye exclusion method, the cellular viabilities of the hepatocytes were $91 \%$ and $94 \%$.

2.6 Incubation of $\left[{ }^{14} \mathrm{C}\right] \mathrm{RGZ}$ with freshly isolated human, rat, and monkey hepatocytes

$\left[{ }^{14} \mathrm{C}\right] \mathrm{RGZ}$ (final concentration: $30 \mu \mathrm{M}$ ) was incubated with human hepatocytes $\left(2 \times 10^{6}\right.$ cells $\left./ \mathrm{mL}\right)$ for $3 \mathrm{~h}$ at $37^{\circ} \mathrm{C}$ under $95 \% \mathrm{O}_{2}$ and $5 \% \mathrm{CO}_{2}$ in an incubator (incubation volume: $2.5 \mathrm{~mL}, n=3$ ). The reactions were terminated by the addition of acetonitrile $(5 \mathrm{~mL})$. The cells homogenized by sonication and the samples of the incubated hepatocytes were stored at approximately $-80^{\circ} \mathrm{C}$ until use. The samples were pooled $(n=3)$ and centrifuged at $21,600 \mathrm{~g}$ for $5 \mathrm{~min}$ at $4^{\circ} \mathrm{C}$ (himac CF $15 \mathrm{D}$; Hitachi Koki Co., Ltd., Tokyo, Japan) and the supernatant was carefully collected. The supernatant was evaporated under a nitrogen stream to an approximate final volume of $1.5 \mathrm{~mL}$. The concentrated sample was used for analysis of the metabolites by radioactivity detection HPLC (radio-HPLC) and LC/MS/MS. The experiments of rat $(n=1)$ and monkey $(n=2)$ were similarly conducted.

\subsection{Incubation of TZD ring $N$-glucuronide with human liver S9}

Incubation of TZD ring $N$-glucuronide (4, authentic standard) with pooled human liver S9 was performed as follows. The incubation mixture contained $10 \mu \mathrm{M}$ TZD ring $N$-glucuronide (dissolved in methanol) and 1 $\mathrm{mg} / \mathrm{mL}$ protein from human liver S9 in $500 \mu \mathrm{L}$ of 50 $\mathrm{mM}$ potassium phosphate $(\mathrm{pH} 7.4)$ in the presence or absence of $2 \mathrm{mM}$ SAM. The incubations were carried out for $2 \mathrm{~h}$ at $37^{\circ} \mathrm{C}$ in a shaking water bath. Control incubation without human liver S9 and with SAM alone was carried out under otherwise similar conditions. Of the $500 \mu \mathrm{L}, 50 \mu \mathrm{L}$ of reactions were terminated by the addition of $100 \mu \mathrm{L}$ of acetonitrile. After centrifugation at $21,600 \mathrm{~g}$ for $5 \mathrm{~min}$ at $4{ }^{\circ} \mathrm{C}$, the supernatant was collected and diluted with $50 \mu \mathrm{L}$ of water and analyzed by liquid chromatography/mass spectrometry (LC/MS) and LC/MS/MS.

\subsection{Radio-HPLC analysis}

Samples from the hepatocyte incubations were analyzed by radio-HPLC. The radio-HPLC analysis was conducted using an L-6000 HPLC system (Hitachi, Ltd., Tokyo, Japan) combined with a radiomatic 525TR radioactivity detector (PerkinElmer Life and Analytical Sciences, Boston, MA, USA). Chromatographic separation was performed on a YMC-Pack ODS-A column $(6.0 \mathrm{~mm} \times 150 \mathrm{~mm}, 5 \mu \mathrm{m}$; YMC Co., Ltd., Kyoto, Japan) at ambient temperature. The mobile phase, consisting of water containing $0.01 \%$ TFA (solvent A) and acetonitrile containing 0.01\% TFA (solvent B), was delivered at a flow rate of $1 \mathrm{~mL} / \mathrm{min}$. The gradient started at $15 \%$ solvent B and increased linearly to 50\% solvent B for $30 \mathrm{~min}$. The column effluent was monitored using an L-4000 UV detector (UV at $247 \mathrm{~nm}$; Hitachi, Ltd.) and a radioactivity detector with a $3 \mathrm{~mL} /$ min flow rate for the Ultima-Flo M liquid scintillator (PerkinElmer Life and Analytical Sciences).

\section{$2.9 \mathrm{LC} / \mathrm{MS}$ and LC/MS/MS analyses}

The conditions described below were used for the $\mathrm{LC} / \mathrm{MS}$ and LC/MS/MS analyses of the human, rat, and monkey hepatocyte metabolites. These analyses were performed using a Q-Tof mass spectrometer 
(Waters, Manchester, UK) with an L-7000 HPLC system (Hitachi, Ltd.) consisting of an intelligent pump (model L-7100), a column oven (model L-7300), a chromatointegrator (model D-7500), and a UV detector (model L7400S). The LC/MS analysis was conducted using ESI in the positive ion mode. The capillary voltage and cone voltage were set at $3,300 \mathrm{~V}$ and $45 \mathrm{~V}$, respectively. The source temperature and desolvation gas temperature were $120^{\circ} \mathrm{C}$ and $300^{\circ} \mathrm{C}$, respectively. The mass range from $\mathrm{m} / z 50$ to 1,000 was acquired with an integration time of $1 \mathrm{~s}$. The LC/MS/MS analysis was performed using a collision energy of $20 \mathrm{eV}$ and xenon as the collision gas. Chromatographic separation was performed on a YMC-Pack ODS-A column $(1.5 \mathrm{~mm} \times$ $150 \mathrm{~mm}, 5 \mu \mathrm{m})$; the column temperature was maintained at $30^{\circ} \mathrm{C}$, and UV detection was carried out at 247 $\mathrm{nm}$. The mobile phase consisted of water containing $0.01 \%$ TFA (solvent A) and acetonitrile containing $0.01 \%$ TFA (solvent B). The gradient started at $15 \%$ solvent B and increased linearly to $50 \%$ solvent B for $30 \mathrm{~min}$. The flow rate was set at $0.1 \mathrm{~mL} / \mathrm{min}$, and the elution flow from HPLC was introduced into the Q-Tof mass spectrometer ionization source through an ESI interface.

The conditions described below were used for the LC/MS and LC/MS/MS analyses of the human liver S9 metabolites. These analyses were performed using a Waters Q-Tof Premier mass spectrometer (Waters, Manchester, UK) with a Waters ACQUITY UPLC system (Waters, Milford, MA, USA) consisting of a binary solvent manager, a sample manager, a photodiode array (PDA) detector, and a column heater. The LC/MS analysis was conducted using ESI in the positive ion mode. The capillary voltage and cone voltage were set at $3,300 \mathrm{~V}$ and $40 \mathrm{~V}$, respectively. The source temperature and desolvation gas temperature were $120^{\circ} \mathrm{C}$ and $300^{\circ} \mathrm{C}$, respectively. The mass range from $\mathrm{m} / \mathrm{z} 50$ to 1,000 was acquired with an integration time of $0.5 \mathrm{~s}$. The LC/MS/MS analysis was performed using a collision energy of $25 \mathrm{eV}$ and argon as the collision gas. Chromatographic separation was performed on a YMC-UltraHT Pro C18 column $(2.0 \times 50 \mathrm{~mm}, 2 \mu \mathrm{m})$; the column temperature was maintained at $40^{\circ} \mathrm{C}$, and $\mathrm{UV}$ detection was carried out at $247 \mathrm{~nm}$. The mobile phase consisted of water containing 0.01\% TFA (solvent A) and acetonitrile containing $0.01 \%$ TFA (solvent B). The gradient started at $10 \%$ solvent $\mathrm{B}$ and increased linearly to $20 \%$ solvent $\mathrm{B}$ for 9 min. The flow rate was set at $0.2 \mathrm{~mL} / \mathrm{min}$, and the elution flow from UPLC was introduced into the Q-Tof Premier mass spectrometer ionization source through an ESI interface.

\section{Results}

\subsection{Metabolic profiles of RGZ in freshly isolated human, rat, and monkey hepatocytes}

Representative radiochromatograms after incubation of $\left[{ }^{14} \mathrm{C}\right] \mathrm{RGZ}$ with freshly isolated human, rat, and monkey hepatocytes are shown in Fig. 3. Seven metabolite peaks in freshly isolated human hepatocytes were

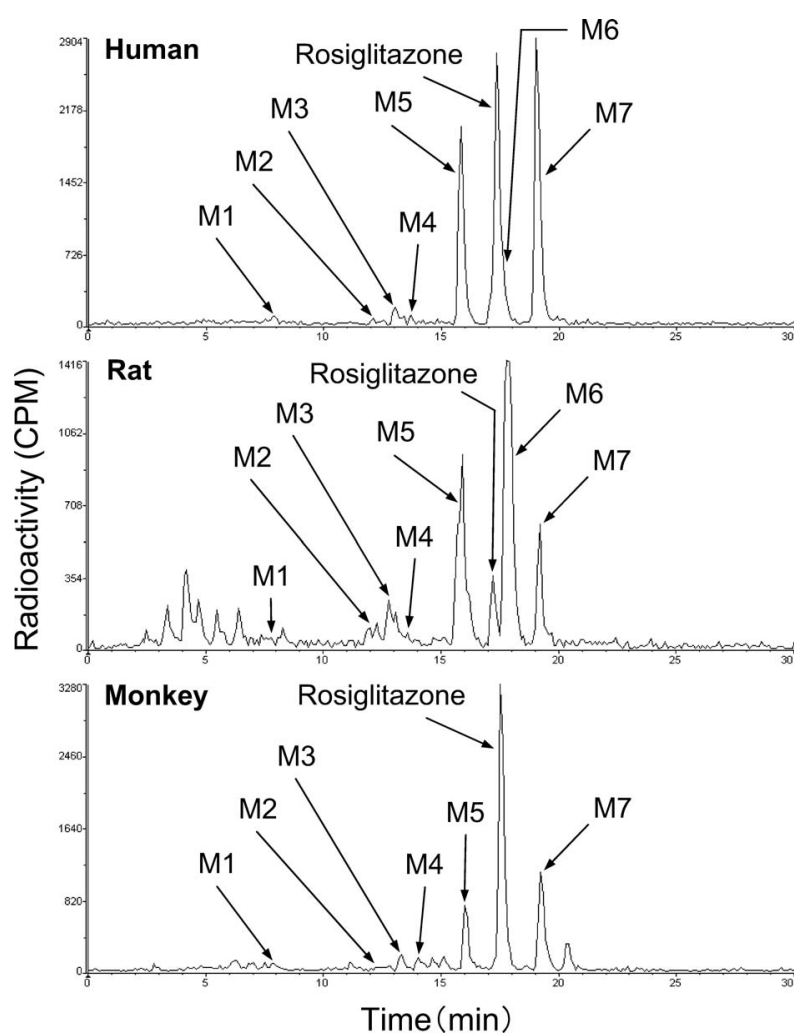

Fig. 3. Representative radiochromatograms after incubation of $\left[{ }^{14} \mathrm{C}\right] \mathrm{RGZ}$ with freshly isolated human, rat, and monkey hepatocytes. $\left[{ }^{14} \mathrm{C}\right] \mathrm{RGZ}$ (final concentration: $30 \mu \mathrm{M})$ was incubated with freshly isolated human, rat, and monkey hepatocytes for $3 \mathrm{~h}$ at $37^{\circ} \mathrm{C}$. Peaks: M1, M2, and M4 are novel metabolites of RGZ, and M3, M5, M6, and M7 are previously reported metabolites of RGZ. Radio-HPLC analysis was conducted as described in Experimental.

Table 1. Positive-Ion LC/MS/MS Data of Metabolites of RGZ in Freshly Isolated Human, Rat, and Monkey Hepatocytes

\begin{tabular}{|c|c|c|c|c|c|c|}
\hline \multirow{2}{*}{ Metabolites } & \multirow{2}{*}{$\begin{array}{l}\text { Retention time } \\
\qquad(\min )\end{array}$} & \multirow{2}{*}{$\begin{array}{c}{[\mathrm{M}+\mathrm{H}]^{+}} \\
m / z\end{array}$} & \multirow{2}{*}{$\begin{array}{l}\text { Product ions } \\
\qquad m / z\end{array}$} & \multicolumn{3}{|c|}{ Freshly isolated hepatocytes } \\
\hline & & & & Human & Rat & Monkey \\
\hline M1 & 7.9 & 552 & $135(\mathrm{~B})^{a}, 287,333,359,376,418$ & $+^{b}$ & + & + \\
\hline M2 & 12.1 & 534 & $135,358(\mathrm{~B})$ & + & + & + \\
\hline M3 & 13.0 & 550 & $151,374(\mathrm{~B})$ & + & + & + \\
\hline M4 & 13.8 & 346 & $120,135(\mathrm{~B}), 255$ & + & + & + \\
\hline M5 & 15.9 & 344 & $107,121(\mathrm{~B}), 133$ & + & + & + \\
\hline M6 & 17.8 & 374 & $136,151(\mathrm{~B})$ & + & + & N.D. ${ }^{c}$ \\
\hline M7 & 19.1 & 374 & $136,151(\mathrm{~B})$ & + & + & + \\
\hline
\end{tabular}

${ }^{a} \mathrm{~B}$ : base peak.

${ }^{b}+$ : metabolite detected.

${ }^{c}$ N.D.: not detected. 
detected and designated as M1, M2, M3, M4, M5, M6, and M7, in order of their retention time in HPLC. M3, M5, M6, and M7 were previously reported metabolites: ${ }^{9),}$ 10) 3-O-glucuronide of RGZ, $N$-desmethyl RGZ, 5hydroxy RGZ, and 3-hydroxy RGZ, respectively (Table 1). M1, M2, and M4 were novel metabolites of RGZ. An identical set of metabolites (M1-M7) was also detected in rat hepatocytes. In monkey hepatocytes, M1-M5 and M7 were also detected. M6 was not detected in monkey hepatocytes in this study.

\subsection{Structure analysis of M2}

The positive-ion LC/MS spectrum of M2 is shown in Fig. 4(a). The protonated molecule $[\mathrm{M}+\mathrm{H}]^{+}$of $\mathrm{M} 2$ was observed at $m / z 534$. Thus, the molecular weight of M 2 was proposed to be 533. The positive-ion LC/MS/MS spectrum of the precursor ion $[\mathrm{M}+\mathrm{H}]^{+}$at $m / z 534$ and the proposed fragmentation scheme of M2 are shown in Fig. 4(b). Product ions at $m / z 135$ and 358 were obtained. The most intense product ion, at $\mathrm{m} / \mathrm{z} 358$, formed via the loss of $176 \mathrm{Da}$ from the ion $[\mathrm{M}+\mathrm{H}]^{+}$at $m / z 534$, corresponding to the glucuronic acid moiety. The fragment ion at $m / z 135$ was formed via elimination of the 5-(4-hydroxybenzyl)-2,4-thiazolidinedione moiety from the ion at $m / z 358$. Therefore, it was suggested that M2 was an $N$-glucuronide of RGZ. Fur- thermore, the positive-ion LC/MS/MS spectrum and HPLC retention time of M2 were identical to those of the authentic standard (4).

Based on these results, M2 was identified as a TZD ring $N$-glucuronide (Fig. 1 ).

\subsection{Structure analysis of M1}

The positive-ion LC/MS spectrum of M1 is shown in Fig. 5(a). The protonated molecule $[\mathrm{M}+\mathrm{H}]^{+}$of $\mathrm{M} 1$ was observed at $m / z 552$, which was 18 Da higher than that of the TZD ring $N$-glucuronide M2. Thus, the molecular weight of M1 was proposed to be 551 . The positiveion LC/MS/MS spectrum of the precursor ion $[\mathrm{M}+\mathrm{H}]^{+}$ at $m / z 552$ and the proposed fragmentation scheme of M1 are shown in Fig. 5(b). Product ions at $m / z 135$, $287,333,359,376$, and 418 were obtained. The most intense product ion, at $m / z 135$, formed via the loss of $417 \mathrm{Da}$ from the ion $[\mathrm{M}+\mathrm{H}]^{+}$at $m / z 552$. The product ion at $m / z 376$ was formed via the loss of $176 \mathrm{Da}$ from the ion $[\mathrm{M}+\mathrm{H}]^{+}$at $m / z 552$, corresponding to the glucuronic acid moiety. Therefore, it was suggested that M1 was a glucuronide metabolite. The product ion at $m / z 418$ was formed via elimination of a part of the glucuronic acid moiety from the ion $[\mathrm{M}+\mathrm{H}]^{+}$at $m / z 552$. The product ions at $m / z 287,333$, and 359 suggested TZD ring metabolism. Therefore, it was
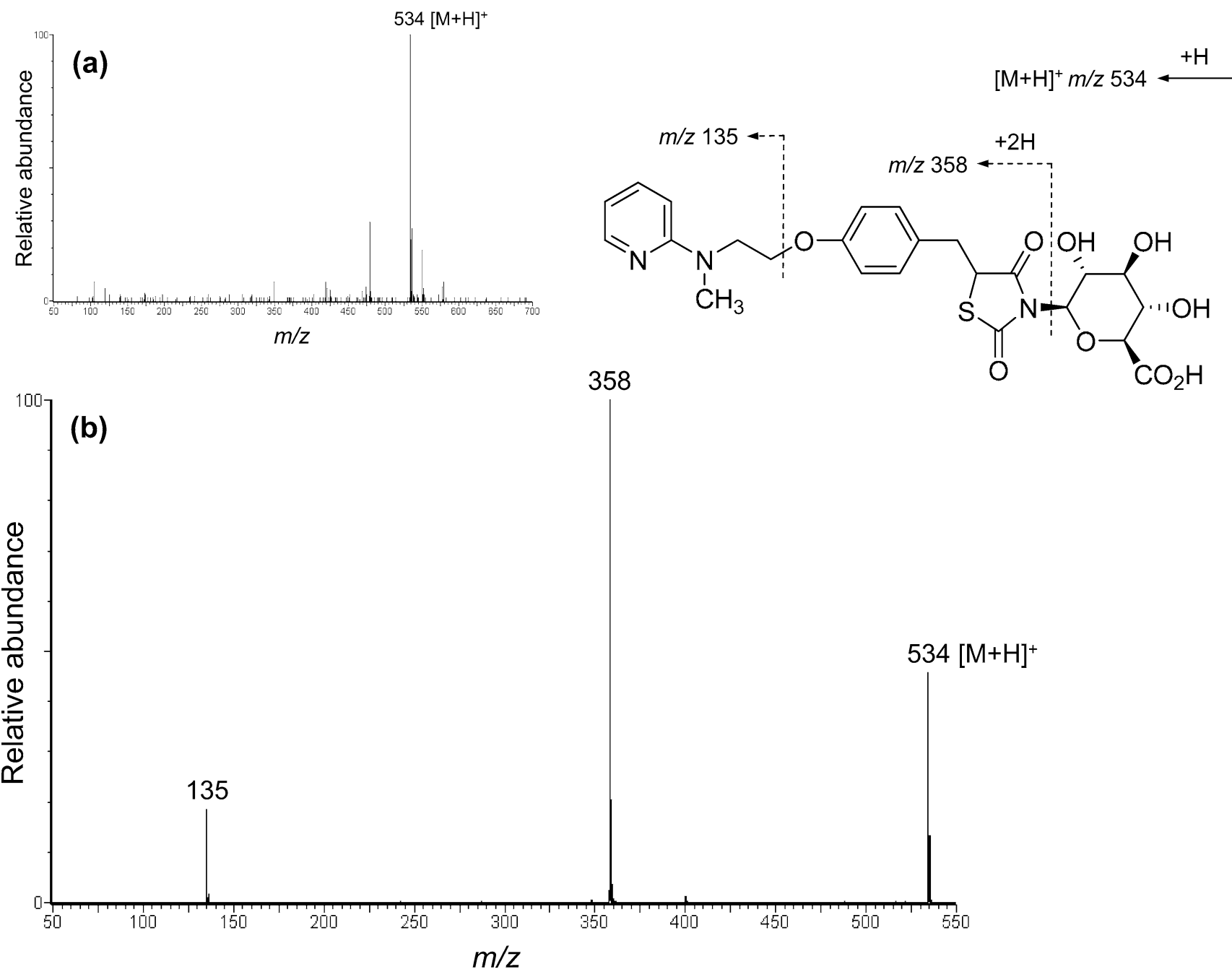

Fig. 4. Proposed fragmentation scheme: (a) Positive-ion LC/MS spectrum and (b) LC/MS/MS spectrum of the ion $[\mathrm{M}+\mathrm{H}]^{+}$at $m / z 534$ of $\mathrm{M} 2$. 

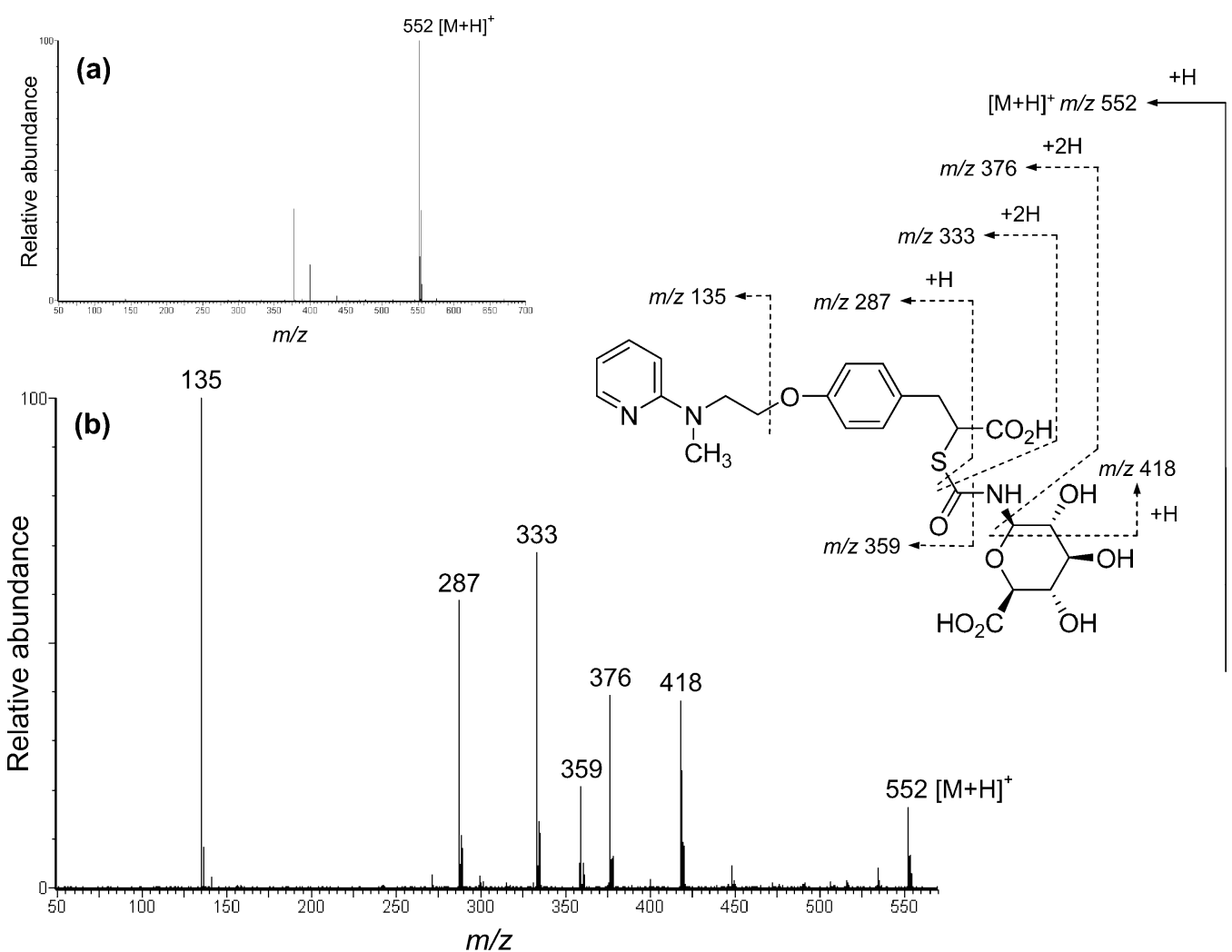

Fig. 5. Proposed fragmentation scheme: (a) Positive-ion LC/MS spectrum and (b) LC/MS/MS spectrum of the ion $[\mathrm{M}+\mathrm{H}]^{+}$at $m / z 552$ of $\mathrm{M} 1$.
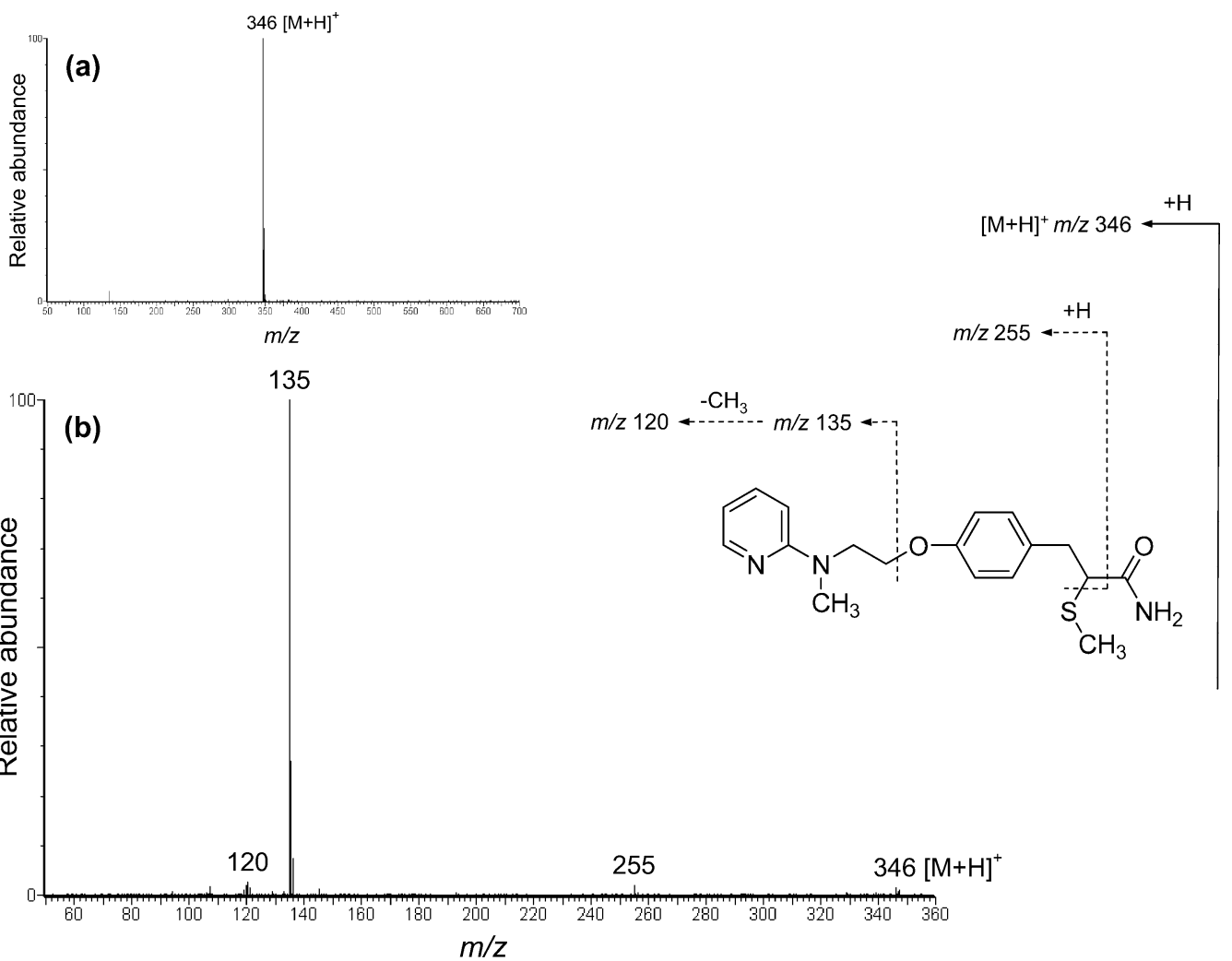

Fig. 6. Proposed fragmentation scheme: (a) Positive-ion LC/MS spectrum and (b) LC/MS/MS spectrum of the ion $[\mathrm{M}+\mathrm{H}]^{+}$at $m / z 346$ of $\mathrm{M} 4$.

proposed that M1 was formed by hydrolysis of the 3,4-amide bond of the TZD ring $N$-glucuronide M2. Furthermore, the positive-ion LC/MS/MS spectrum and HPLC retention time of M1 were identical to those of the authentic standard (5).

Based on these results, M1 was identified as TZD 
ring-opened $N$-glucuronide, a hydrolyzed metabolite of TZD ring $N$-glucuronide M2 (Fig. 1 ).

\subsection{Structure analysis of M4}

The positive-ion LC/MS spectrum of M4 is shown in Fig. 6(a). The protonated molecule $[\mathrm{M}+\mathrm{H}]^{+}$of $\mathrm{M} 4$ was observed at $m / z 346$. Thus, the molecular weight of M4 was proposed to be 345 . The positive-ion LC/MS/ MS spectrum of the precursor ion $[\mathrm{M}+\mathrm{H}]^{+}$at $m / z 346$ and the proposed fragmentation scheme of M4 are shown in Fig. 6(b). Product ions at $m / z 120,135$, and 255 were obtained. The most intense product ion, at $m / z 135$, formed via the loss of $211 \mathrm{Da}$ from the ion $[\mathrm{M}+\mathrm{H}]^{+}$at $m / z 346$. The product ions at $m / z 120$ and 135 indicated that the 2-methyl-2-(pyridinylamino)ethyl moiety was not modified. On the other hand, the product ion at $m / z 255$ from the ion $[\mathrm{M}+\mathrm{H}]^{+}$at $m / z 346$ suggested TZD ring metabolism. The product ion at $m / z 255$ was formed via elimination of the methylmercapto and amide groups from the ion $[\mathrm{M}+\mathrm{H}]^{+}$at $m / z 346$.

Based on these results, M4 was proposed to be a TZD ring-opened methylmercapto amide (Fig. 1).

\subsection{Metabolism of TZD ring $N$-glucuronide in human liver S9}

The metabolism of TZD ring $N$-glucuronide (M2) was studied with human liver S9. Incubation of M2 with human liver S9 in the presence of SAM yielded TZD ring-opened $N$-glucuronide $\mathrm{M} 1$ and human liver S9 metabolites S9M1 and S9M2 (Fig. 7). Incubation of M2 with human liver S9 in the absence of SAM yielded M1 and S9M1 (data not shown). M1 and S9M1 also resulted from incubation of M2 without human liver S9 and with SAM alone (data not shown).

\subsection{Structure analysis of S9M1}

The positive-ion LC/MS spectrum of S9M1 is shown in Fig. 8(a). The protonated molecule $[\mathrm{M}+\mathrm{H}]^{+}$of S9M1 was observed at $m / z$ 333. Thus, the molecular weight of S9M1 was proposed to be 332. The positive-ion LC/ $\mathrm{MS} / \mathrm{MS}$ spectrum of the precursor ion $[\mathrm{M}+\mathrm{H}]^{+}$at $m / z$ 333 and the proposed fragmentation scheme of S9M1 are shown in Fig. 8(b). Product ions at $m / z 120,135$, 255 , and 287 were obtained. The most intense product ion, at $m / z 135$, formed via the loss of $198 \mathrm{Da}$ from the ion $[\mathrm{M}+\mathrm{H}]^{+}$at $m / z 333$. The product ions at $m / z 120$ and 135 indicated that the 2-methyl-2-(pyridinylamino)ethyl moiety was not modified. On the other hand, the product ions at $m / z 255$ and 287 from the ion $[\mathrm{M}+\mathrm{H}]^{+}$ at $m / z 333$ suggested TZD ring metabolism. The product ion at $m / z 287$ was formed via elimination of the carboxylic acid moiety from the ion $[\mathrm{M}+\mathrm{H}]^{+}$at $m / z$ 333. The product ion at $\mathrm{m} / z 255$ was formed via elimination of the mercapto and carboxylic acid groups from the ion $[\mathrm{M}+\mathrm{H}]^{+}$at $m / z 333$.

Based on these results, S9M1 was proposed to be a TZD ring-opened mercapto carboxylic acid.

\subsection{Structure analysis of S9M2}

The positive-ion LC/MS spectrum of S9M2 is shown in Fig. 9(a). The protonated molecule $[\mathrm{M}+\mathrm{H}]^{+}$of S9M2 was observed at $m / z 347$, which was 14 Da higher than that of S9M1. Thus, the molecular weight of S9M2 was proposed to be 346 . The positive-ion LC/MS/MS spectrum of the precursor ion $[\mathrm{M}+\mathrm{H}]^{+}$at $m / z 347$ and the proposed fragmentation scheme of S9M2 are shown in Fig. 9(b). Product ions at $m / z 120,135,255$, and 287 were obtained. The most intense product ion, at $\mathrm{m} / \mathrm{z}$ 135, was formed via the loss of $212 \mathrm{Da}$ from the ion $[\mathrm{M}+\mathrm{H}]^{+}$at $m / z 347$. The product ions at $m / z 120$ and 135 indicated that the 2-methyl-2-(pyridinylamino)ethyl moiety was not modified. On the other hand, the product ions at $m / z 255$ and 287 from the ion $[\mathrm{M}+\mathrm{H}]^{+}$ at $m / z 347$ suggested TZD ring metabolism. The product ion at $m / z 287$ was formed via elimination of the methyl and carboxylic acid groups from the ion $[\mathrm{M}+\mathrm{H}]^{+}$at $m / z 347$. The product ion at $m / z 255$ was formed via elimination of the methylmercapto and carboxylic acid groups from the ion $[\mathrm{M}+\mathrm{H}]^{+}$at $m / z$ 347.

Based on these results, S9M2 was proposed to be a TZD ring-opened methylmercapto carboxylic acid produced by the methylation of the mercapto group of

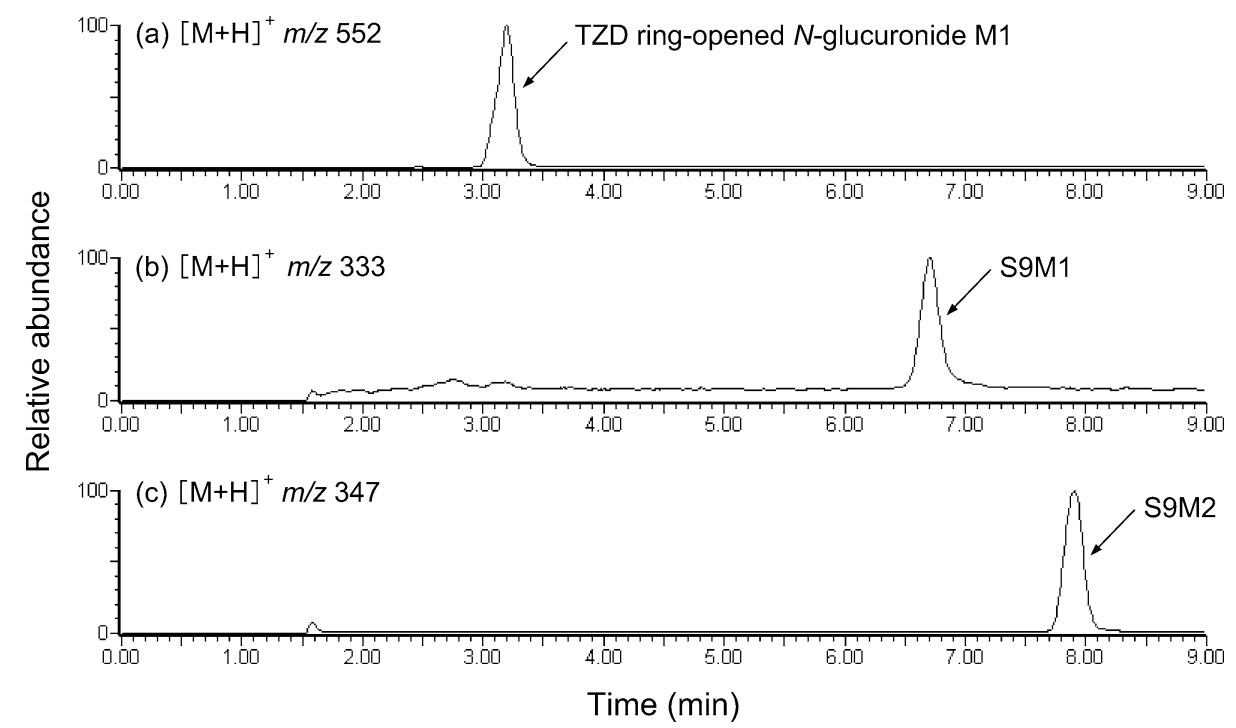

Fig. 7. Extracted ion chromatograms of the metabolites after incubation of M2 with human liver S9 in the presence of SAM. (a) $[\mathrm{M}+\mathrm{H}]^{+}$at $m / z 552$ of TZD ring-opened $N$-glucuronide $\mathrm{M} 1$, (b) $[\mathrm{M}+\mathrm{H}]^{+}$at $m / z 333$ of S9M1, and (c) $[\mathrm{M}+\mathrm{H}]^{+}$at $m / z 347$ of S9M2. Positive-ion LC/MS analysis was conducted as described in Experimental. 

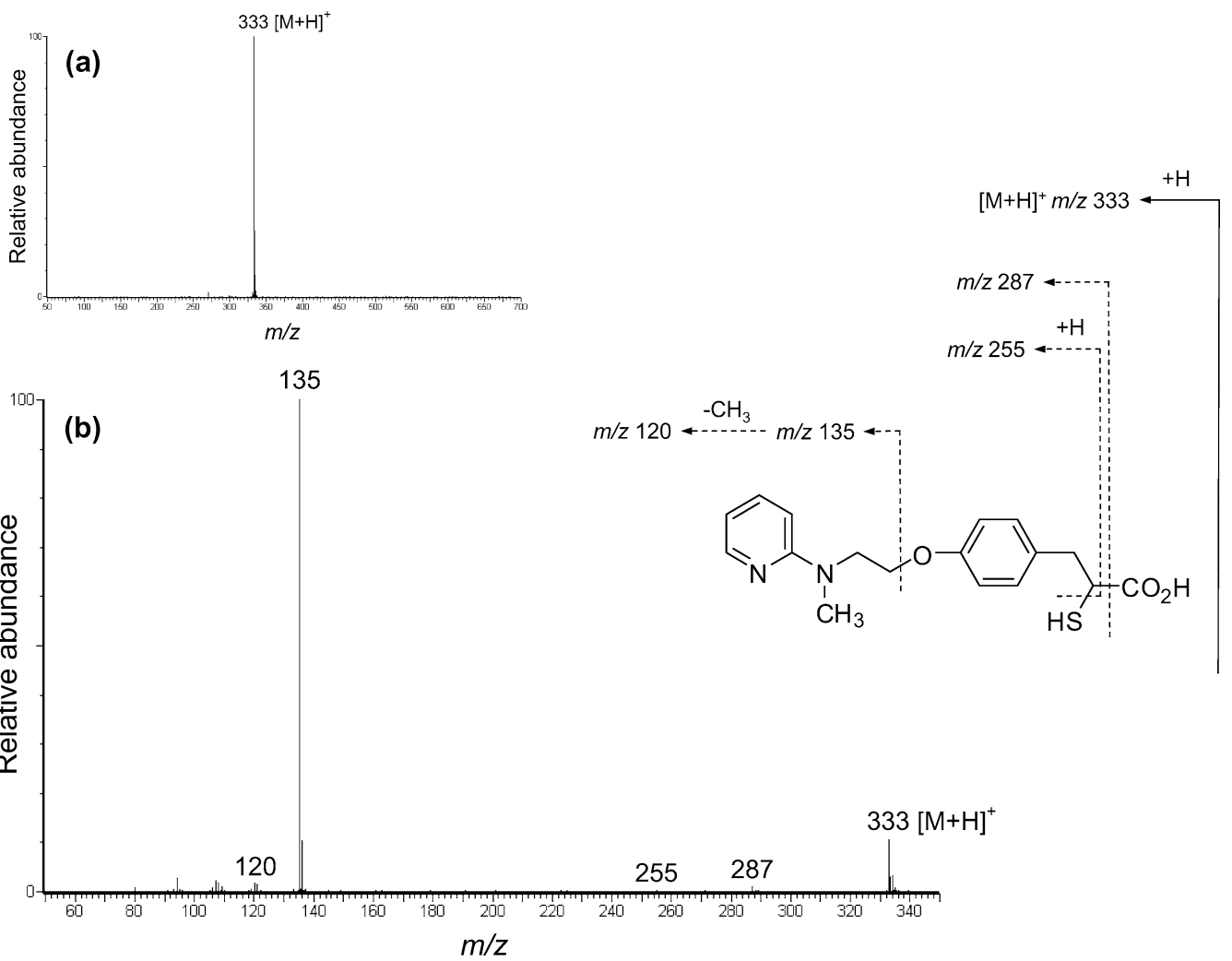

Fig. 8. Proposed fragmentation scheme: (a) Positive-ion LC/MS spectrum and (b) LC/MS/MS spectrum of the ion $[\mathrm{M}+\mathrm{H}]^{+}$at $m / z 333$ of S9M1.
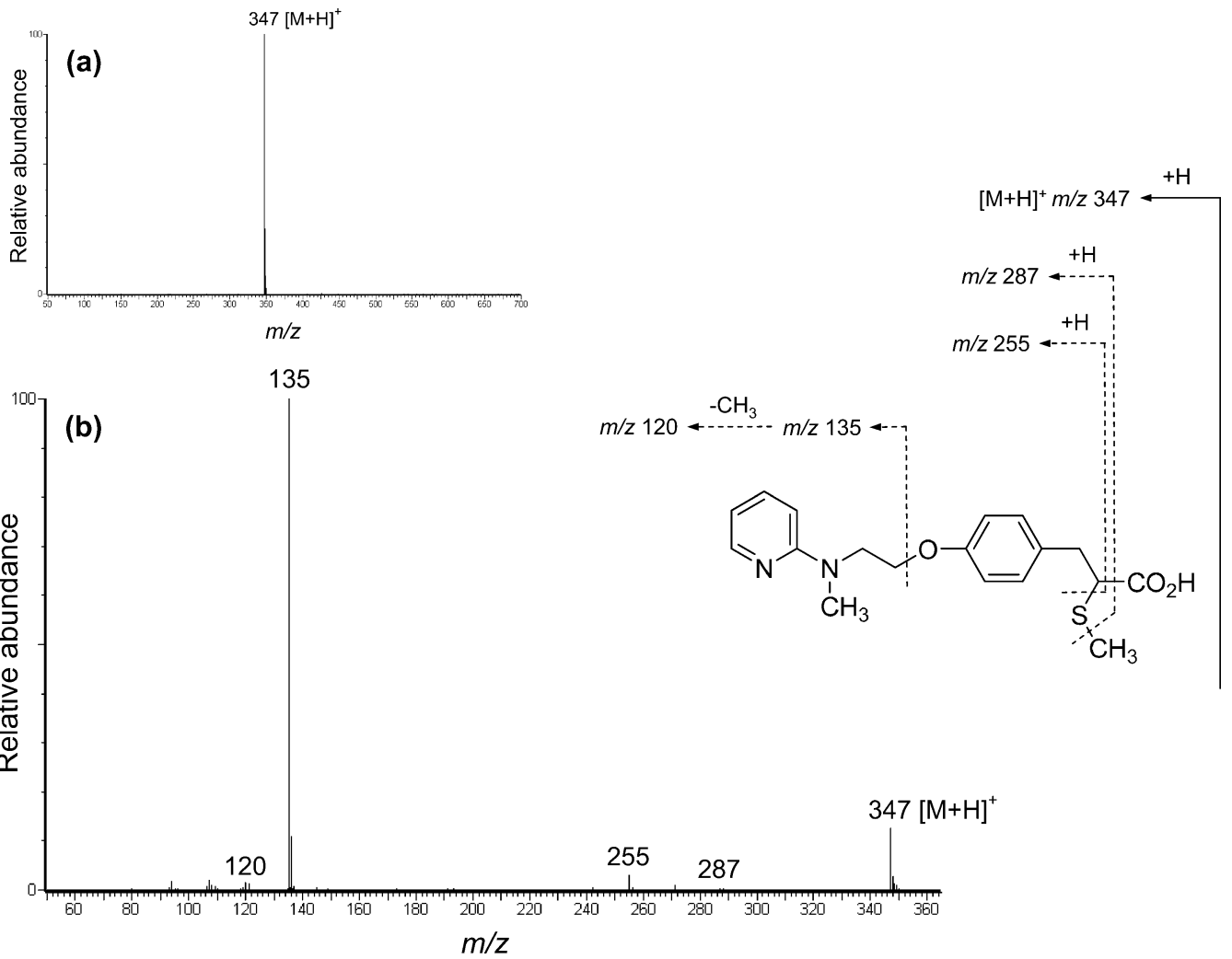

Fig. 9. Proposed fragmentation scheme: (a) Positive-ion LC/MS spectrum and (b) LC/MS/MS spectrum of the ion $[\mathrm{M}+\mathrm{H}]^{+}$at $m / z 347$ of S9M2. 


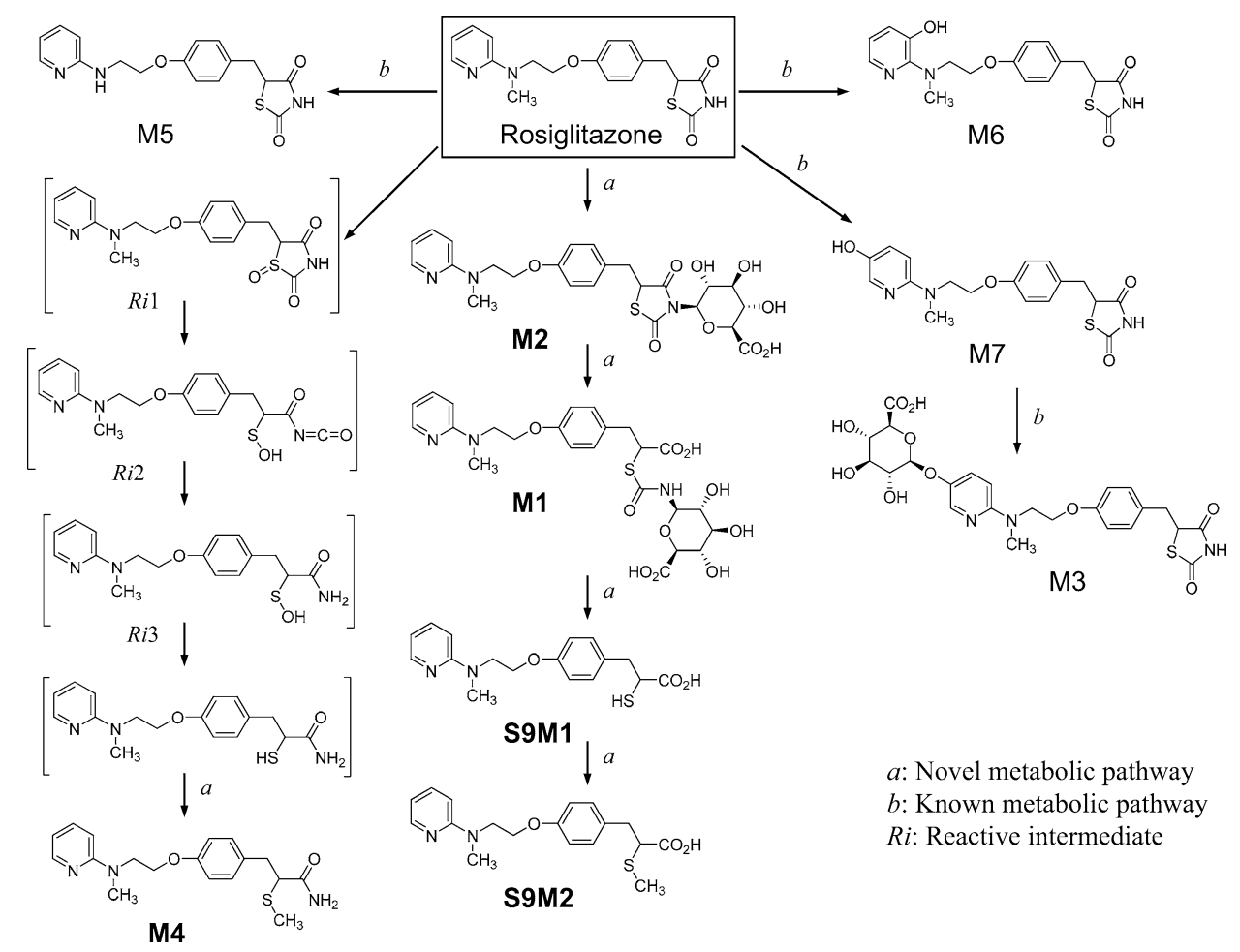

Fig. 10. Proposed in vitro metabolic pathways for RGZ. Bold indicates that metabolites M1, M2, M4, S9M1, and S9M2 were novel metabolites of RGZ. The metabolic pathways $(b)$ were proposed by Bolton et al. ${ }^{9)}$ and Cox et al. ${ }^{10)}$

S9M1. Moreover, similar S-methyl metabolites reported in the TZD derivative MK-076724)-26) support the above proposal.

\section{Discussion}

In this study, we detected seven metabolites (M1M7) in an in vitro metabolic system of RGZ with freshly isolated human, rat, and monkey hepatocytes and their structures were elucidated by LC/MS/MS. Furthermore, metabolites M1, S9M1, and S9M2 were detected in an in vitro metabolic system with human liver S9 using M2 (authentic standard) as a substrate. Based on the structures of the elucidated metabolites, the in vitro metabolic pathways for RGZ are proposed, as shown in Fig. 10 .

Minor but novel metabolic pathways for RGZ, $N$ glucuronidation of the TZD ring of RGZ to form M2 and hydrolysis of M2 to form M1, were observed in hepatocytes. $N$-Glucuronides of heterocyclic compounds have been reported, e.g., a glucuronide on a nitrogen of a benzoxazin-2-one moiety of efaviren $z^{27}$ and a glucuronide on a nitrogen of an imidazole moiety of imidafenacin. ${ }^{28)}$ However, $N$-glucuronide of a TZD ring is first reported in this study.

As a result of the presence of these metabolites, a novel metabolic pathway via the TZD ring $N$ glucuronide M2 and subsequent hydrolysis to the TZD ring-opened $N$-glucuronide M1 is proposed. This TZD ring opening pathway is distinct from the known oxidative TZD ring opening pathway for TGZ. ${ }^{15}$ )

Moreover, in the human liver S9 study using M2, we inferred that M2 is metabolized to S9M1 via M1 and consequently metabolized to S9M2 immediately in the presence of SAM. These are also novel metabolic pathways for RGZ.
The known oxidative TZD ring opening and subsequent pathways via reactive intermediate generation of TGZ have been proposed on the basis of identification of glutathione conjugate metabolites using human liver microsomes and cDNA-expressed cytochrome P450 isoforms. ${ }^{15)}$ Similar metabolic pathways have been reported in PGZ, ${ }^{29)}$ the TZD derivatives MK076724-26) and MRL-A ${ }^{30)}$ in the in vitro systems. In the case of RGZ, a glutathione trapped reactive intermediate ( $\alpha$-ketoisocyanate) has been proposed. ${ }^{31)}$ In this study, we have identified M4 as a novel metabolite of RGZ via TZD ring-opened mercapto amide. We estimate that this metabolite is sequentially generated by the oxidative TZD ring opening and subsequent pathways.

Besides those described above, the known metabolic pathways for $\mathrm{RGZ}^{9), 10)}$ were also confirmed in this study, i.e., 1) generation of the $N$-desmethyl RGZ (M5) and the 5-hydroxy RGZ (M6) and 2) generation of the 3-O-glucuronide of RGZ (M3) via the 3-hydroxy RGZ (M7).

Some toxicological concerns have been expressed regarding the oxidative TZD ring opening reaction in the TZD-containing drugs. However, the elucidated novel metabolites and the proposed metabolic pathway in this study suggest the involvement of $N$-glucuronide on detoxification of the TZD-containing drugs.

\section{Acknowledgements}

We thank Dr. Hideyuki Shiozawa and Dr. Osamu Okazaki, Drug Metabolism and Pharmacokinetics Research Laboratories, Daiichi Sankyo Co., Ltd., for their careful reading of the document and their scientific expertise. 


\section{References}

1) J. Patel, E. Miller, R. Patwardhan, and Rosiglitazone 011 Study Group, Diabetes, 47(Suppl. 1), A17 (1998).

2) P. W. Young, et al., J. Pharmacol. Exp. Ther., 248, 751 (1998).

3) D. R. Matthews, A. Bakst, W. M. Weston, and P. Hemyari, Diabetologia, 42(Suppl. 1), A228 (1999).

4) J. M. Lehmann, L. B. Moore, T. A. Smith-Oliver, W. O. Wilkison, T. M. Willson, and S. A. Kliewer, Biol. Chem., 270, 12953 (1995).

5) A. R. Saltiel and J. M. Olefsky, Diabetes, 45, 1661 (1996).

6) S. L. Pearson, M. A. Cawthorn, J. C. Clapham, S. L. Dunmore, S. D. Holmes, G. B. T. Moore, S. A. Smith, and M. Tadayyon, Biochem. Biophys. Res. Commun., 229, 752 (1996).

7) J. Berger, P. Bailey, C. Biswas, C. A. Cullinan, T. W. Doebber, N. S. Hayes, R. Saperstein, R. G. Smith, and M. D. Leibowitz, Endocrinology, 137, 4189 (1996).

8) T. M. Willson, J. E. Cobb, D. J. Cowan, R. W. Wiethe, I. D. Correa, S. R. Prakash, K. D. Beck, L. B. Moore, S. A. Kliewer, and J. M. Lehmann, J. Med. Chem., 39, 665 (1996).

9) G. C. Bolton, J. P. Keogh, P. D. East, F. J. Hollis, and A. D. Shore, Xenobiotica, 26, 627 (1996).

10) P. J. Cox, D. A. Ryan, F. J. Hollis, A.-M. Harris, A. K. Miller, M. Vousden, and H. Cowley, Drug Metab. Dispos., 28, $772(2000)$.

11) C. E. C. A. Hop, P. R. Tiller, and L. Romanyshyn, Rapid Commun. Mass Spectrom., 16, 212 (2002).

12) S. J. Baldwin, S. E. Clarke, and R. J. Chenery, Br. J. Clin. Pharmacol., 48, 424 (1999).

13) E. A. M. Gale, Lancet, 357, 1870 (2001).

14) D. J. Graham, L. Green, J. R. Senior, and P. Nourjah, Am. J. Med., 114, 299 (2003).

15) K. Kassahun, P. G. Pearson, W. Tang, I. McIntosh, K. Leung, C. Elmore, D. Dean, R. Wang, G. Doss, and T. A. Baillie, Chem. Res. Toxicol., 14, 62 (2001).

16) J. N. Tettey, J. L. Maggs, W. G. Rapeport, M. Pirmohamed, and B. K. Park, Chem. Res. Toxicol., 14, 965 (2001).

17) M. T. Smith, Chem. Res. Toxicol., 16, 679 (2003).
18) K. He, R. E. Talaat, W. F. Pool, M. D. Reily, J. E. Reed, A. J. Bridges, and T. F. Woolf, Drug Metab. Dispos., 32, 639 (2004).

19) Y. Yamamoto, H. Yamazaki, T. Ikeda, T. Watanabe, H. Iwabuchi, M. Nakajima, and T. Yokoi, Drug Metab. Dispos., 30, 155 (2002).

20) R. Alvarez-Sanchez, F. Montavon, T. Hartung, and A. Pahler, Chem. Res. Toxicol., 19, 1106 (2006).

21) K. G. Madsen, G. Gronberg, C. Skonberg, U. Jurva, S. H. Hansen, and J. Olsen, Chem. Res. Toxicol., 21, 2035 (2008).

22) T. S. Weiss, S. Pahernik, I. Scheruebl, K.-W. Jauch, W. E. Thasler, J. Hepatol., 38, 476 (2003).

23) P. Moldeus, J. Hogberg, and S. Orrenius, Methods Enzymol., 52, 60 (1978).

24) B. V. Karanam, C. E. C. A. Hop, D. Q. Liu, M. Wallace, D. Dean, H. Satoh, M. Komuro, K. Awano, and S. H. Vincent, Drug Metab. Dispos., 32, 1015 (2004).

25) D. Q. Liu, B. V. Karanam, G. A. Doss, R. R. Sidler, S. H. Vincent, and C. E. C. A. Hop, Drug Metab. Dispos., 32, 1023 (2004).

26) C. J. Kochansky, et al., Drug Metab. Dispos., 34, 1457 (2006).

27) A. E. Mutlib, H. Chen, G. A. Nemeth, J. A. Markwalder, S. P. Seitz, L. S. Gan, and D. D. Christ, Drug Metab. Dispos., 27, 1319 (1999).

28) S. Ohmori, M. Miura, C. Toriumi, Y. Satoh, and T. Ooie, Drug Metab. Dispos., 35, 1624 (2007).

29) T. M. Baughman, R. A. Graham, K. Wells-Knecht, I. S. Silver, L. O. Tyler, M. Wells-Knecht, and Z. Zhao, Drug Metab. Dispos., 33, 733 (2005).

30) V. B. G. Reddy, B. V. Karanam, W. L. Gruber, M. A. Wallace, S. H. Vincent, R. B. Franklin, and T. A. Baillie, Chem. Res. Toxicol., 18, 880 (2005).

31) J. R. Soglia, S. P. Harriman, S. Zabrina, J. Barberia, M. J. Cole, J. G. Boyd, and L. G. Contillo, J. Pharm. Biomed. Anal., 36, 105 (2004).

Keywords: Rosiglitazone, Thiazolidinedione ring, $N$ Glucuronidation, Freshly isolated hepatocytes, LC/MS/MS 